\title{
THE POSSIBILITY OF USING IMAGES OBTAINED FROM THE UAS IN CADASTRAL WORKS
}

\author{
Z. Kurczynski ${ }^{\text {a, }}$, K. Bakuła ${ }^{\text {a }}$, M. Karabin ${ }^{\text {a }}$, M. Kowalczyk ${ }^{\text {a }}$, J. S. Markiewicz ${ }^{\text {a }}$, W. Ostrowski ${ }^{\text {a }}$ P. Podlasiak ${ }^{\text {a }}$, D. Zawieska ${ }^{\text {a }}$ \\ ${ }^{a}$ Warsaw University of Technology, Faculty of Geodesy and Cartography, Warsaw, Poland \\ kurczynski@wp.pl, (k.bakula, m.karabin,m.kowalczyk, j.markiewicz,w.ostrowski, p.podlasiak, d.zawieska)@gik.pw.edu.pl
}

\author{
Inter Commission ICWG I/Vb
}

KEY WORDS: UAS/UAV, cadastral map, cadastre, buildings, parcels, photogrammetric measurements

\begin{abstract}
:
Updating the cadastre requires much work carried out by surveying companies in countries that have still not solved the problem of updating the cadastral data. In terms of the required precision, these works are among the most accurate. This raises the question: to what extent may modern digital photogrammetric methods be useful in this process? The capabilities of photogrammetry have increased significantly after the introduction of digital aerial cameras and digital technologies. For the registration of cadastral objects, i.e., land parcels' boundaries and the outlines of buildings, very high-resolution aerial photographs can be used. The paper relates an attempt to use an alternative source of data for this task - the development of images acquired from UAS platforms. Multivariate mapping of cadastral parcels was implemented to determine the scope of the suitability of low altitude photos for the cadastre. In this study, images obtained from UAS with the GSD of $3 \mathrm{~cm}$ were collected for an area of a few square kilometres. Bundle adjustment of these data was processed with sub-pixel accuracy. This led to photogrammetric measurements being carried out and the provision of an orthophotomap (orthogonalized with a digital surface model from dense image matching of UAS images). Geometric data related to buildings were collected with two methods: stereoscopic and multi-photo measurements. Data related to parcels' boundaries were measured with monoplotting on an orthophotomap from low-altitude images. As reference field surveying data were used. The paper shows the potential and limits of the use of UAS in a process of updating cadastral data. It also gives recommendations when performing photogrammetric missions and presents the possible accuracy of this type of work.
\end{abstract}

\section{INTRODUCTION}

The cadastre is undoubtedly the most important and oldest public registry maintained by the districts, with strong support from private land surveyors (the surveying industry). The real estate cadastre includes information on:

1) lands (cadastral parcels) - their location, boundaries, area, land use types, soil classes, designation in the land register or files of documents, if they exist for given real estates, including the discussed lands,

2) buildings - their location, destination, useful functions, general technical specifications,

3) premises - their location, useful functions and size.

However, the following information is also presented in the real estate cadastre:

- the owner, and, in the case of state and local government lands, other individuals or entities, which are the possessors of lands and buildings or their parts,

- places of residence or headquarters of the abovementioned individuals or entities,

- information on registration in a register of monuments,

- real estate values.

From a technical point of view, the cadastre is divided into two parts: the descriptive part and the cartographic part (cadastral maps). The process called the "modernization of the cadastre". It consists of a new measurement of land parcels' boundaries, buildings' measurements (outlines of buildings), the unification of co-ordinate systems, etc. Modernization of the cadastre requires a lot of work carried out by surveying companies. A large part of this process has already been performed with the use of existing analogue cadastral maps. The challenge, in this context, is to convert data from maps that have been digitized to data from field surveys. A major problem is the lack of archive data and the need for collecting data on land parcels that obstruct the setting of boundaries in the field, which has recently also involved photogrammetric technologies (Kurczyński and Bakuła, 2015). In most cases, the parcels' boundaries are not marked on the ground with permanent marks. In terms of the required precision, these works are the ones of the most accurate operations. The localization of cadastral parcels' boundaries should be identified with the use of field surveys of mean error values not larger than $0.30 \mathrm{~m}$ regarding the first-class geodetic control, while the buildings' corners should be identified with a measurement accuracy of not less than $0.10 \mathrm{~m}$ regarding the closest points of geodetic or measurement control points. Considering the accuracies of the geodetic control points of classes lower than the first class and accuracies of the measurement control - the geometric data concerning buildings' corners regarding the first-class geodetic control also have to meet the accuracy criterion of $0.30 \mathrm{~m}$. These requirements are very high.

Several examples of research works exist that present the potential of photogrammetric methods for the application in the cadastre (Schermerhorn and Witt, 1954; Weissmann, 1971;

\footnotetext{
* Corresponding author
} 
Dale, 1979; Srinivas et al., 2012 Kurczyński and Bakuła, 2015). The large-scale photogrammetric images taken with the so-called large format digital cameras have begun to be used recently on a wider scale. Images with the resolution (ground pixels) of $0.05-0.10 \mathrm{~m}$ are used, often with the side overlap increased to $60 \%$. The photogrammetric methods are used during the different stages of modernization of the cadastre. Some restrictions are connected with existing legal regulations and legal and technical difficulties resulting from historical conditions.

In parallel, the rapid development of low-altitude photogrammetry has been observed in the last few years, i.e., photogrammetry based on the processing of images registered with unmanned platforms such as UAS (Colomina and Molina, 2014). The development of platforms and sensors is accompanied by the development and dissemination of computerized methods and tools for the processing of such images. A very high resolution of images allows us to obtain highly accurate measurements, but at the expense of limiting the areas of studies. Many surveying technologies can be used in cadastral works (Jazayeri et al, 2014). One of them is UAS technology and there are high expectations related to its use (Kelm, 2014) while practically, due to many limitations, only some preliminary studies have been performed (i.e. Manyoky et al., 2012; Kędzierski et al., 2015).

The objective of this paper is to evaluate the possibilities of using low-altitude photogrammetry for update of the cadastre data, specifically for measurements of corners of buildings and the acquisition of data related to cadastral parcels boundaries. This objective can be seen in terms of two dimensions: technical and economical. In the technical dimension, the measurement possibility and accuracy should be identified and, in the economical dimension, the justification of the advisability of using UAS images for this purpose should be discussed. The territorial coverage of the works excludes the use of low-altitude photogrammetry as a leading source of data, but for small objects low-altitude images may be a rational alternative to large-format photogrammetry. This justifies and motivates us to undertake the tasks specified by the objective of the project.

\section{EXPERIMENT}

\subsection{The experiment's range}

The objective of the ongoing work is to determine the measurement's potential for low-altitude images, acquired by unmanned aerial systems (UAS). This potential is observed in the context of the utilization of such images for tasks related to updating the cadastre, including: measurements of buildings' corners and the acquisition of cadastral parcel boundary data.

The effect of "building lean", visible on traditional orthophotomaps, practically excludes their use for this purpose. This is also true in the case of an orthophotomap generated using software for the low-altitude data processing, which creates an orthophotomap looking more like a true orthophotomap, because orthorectification with the use of a high-resolution digital surface model (DSM), the utilization of such a product is not possible as the corners of buildings are obscured by roofs (eaves). The stereoscopic measurements of roof edges are hindered by existing roof eaves which means that the roof outlines usually do not coincide with the outlines of buildings (with the required high accuracy of measurements). Therefore, two measurement techniques have been examined:

- the stereoscopic measurements of building outlines, directly visible on the stereoscopic models (far from the principal point of images),

- monocular measurements of buildings' corners on all images where outlines or considered points of outlines are directly visible (multi-photo intersection).

The assumption of (stereo or mono) measurements of directly visible outlines and buildings' corners means that such measurements are hindered for buildings localized in the nadir fragments of images, and the localization of measured buildings near the edges of images is desirable. The increased image overlap (end- and side overlap) significantly increases the chances and accuracy of measurements (each outline is projected and visible on more images).
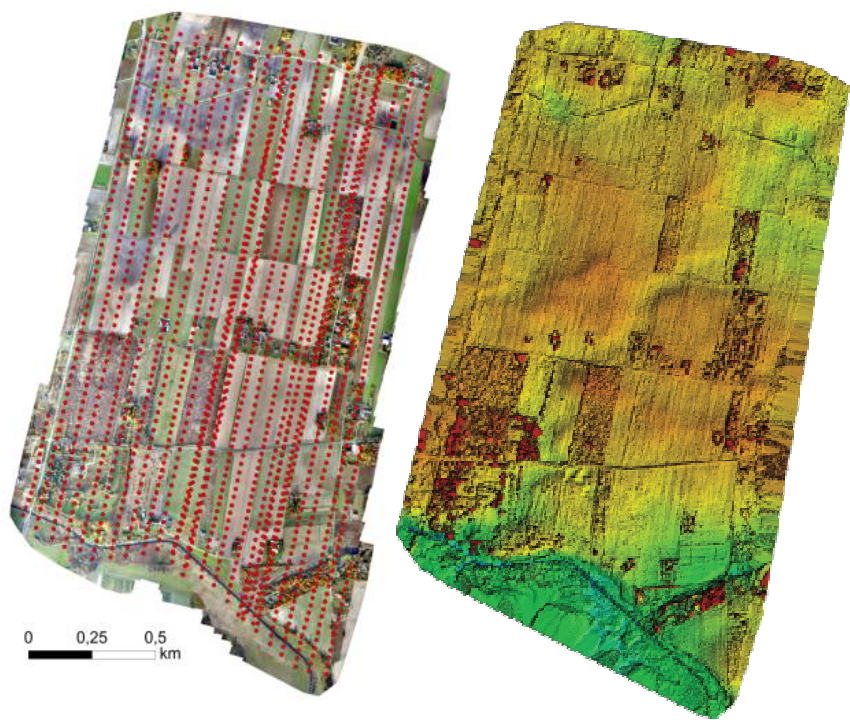

Figure 1. The test area of the Podkampinos cadastral district, the Kampinos Municipality, Mazovia Voivodship, the resulting orthophotomap with marked image centres and the digital surface model (DSM)

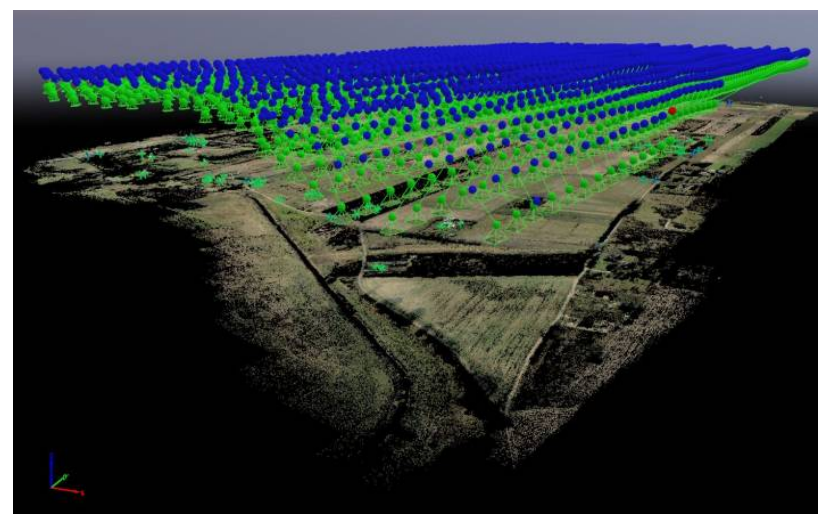

Figure 2. The perspective view of UAS images registered for the test area with visible tie-points

For the measurements of boundary points, the monoplotting of digital orthophotomaps generated from UAS images was selected as a leading measurement technique based on aerial photogrammetry. It meets the legal accuracy requirements of the planimetric point localization with an error value lower than $0.30 \mathrm{~m}$ regarding the points of the first-class geodetic control. 


\subsection{The test object and UAS images}

As a test object, the Podkampinos cadastral district located in the Kampinos Municipality (about $40 \mathrm{~km}$ north-west of Warsaw) was selected. It is a rural area of about $3 \mathrm{~km}^{2}$ with small agricultural parcels and village buildings (Figure 1). This area was covered by colour images acquired from a fixed-wing platform, registered during one working day. The images were taken with the SONY $\alpha$ 7R camera equipped with the FE 2/28 lens, and the CMOS sensor of $35.8 \mathrm{~mm} \times 23.9 \mathrm{~mm}$ size and resolution of $7380 \times 4912$ pixels (36Mpx). The camera mount was oriented with a longer side in the flight's direction. Images were designed to be of $0.03 \mathrm{~m} \mathrm{GSD}, \mathrm{p}=80 \%$ end overlap and $\mathrm{q}=60 \%$ side overlap. A total of 1660 images was registered (Figure 2). Twenty-one control points were marked on the study area. Their locations were measured with the use of the Global Navigation Satellite System Real-Time Network (GPSRTN) using the area corrections from ASG-EUPOS reference stations.

\subsection{The reference data}

For the test area, the updated cadastral data exist in a digital form, including parcels' boundaries and buildings' outlines in the geometrical part (Figure 3). As with the acquisition of data for the cadastre, the digitization of analogue maps was unfortunately used, it might be possible that some data points defining the building outlines (buildings' corners) did not meet the accuracy criteria used for direct filed surveys. Some of the buildings could have been developed or modernized (the insulation of buildings' walls) during the period between the updating of the cadastre and the experiment, which would also result in differences between the geometric data from the map and the real data (field data) obtained via the UAS platform. Therefore, it was decided to perform the additional field measurements of buildings' corners.

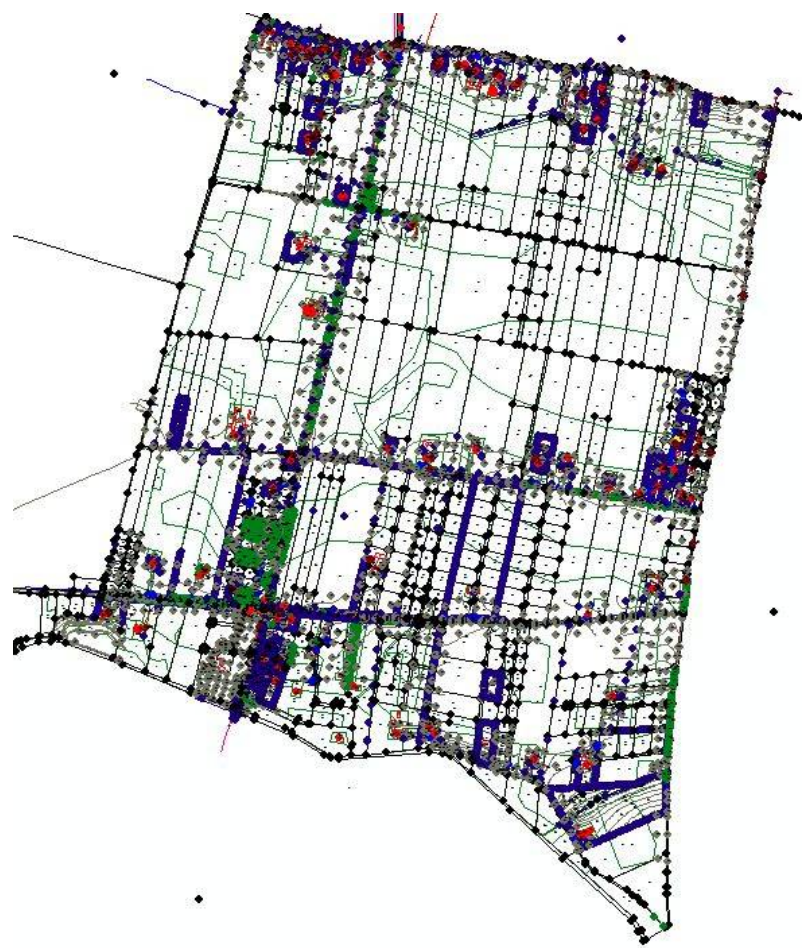

Figure 3 . The vector form of cadastral data after updating with traditional methods
More than 100 buildings' corners were measured directly in the field with the use of GNNS (GPS-RTN) technology with KOLIDA K-9T GNSS ROVER and KOLIDA S10 controller, using the area corrections from ASG-EUPOS reference stations. It was an offset measurement; therefore, calculation of locations of buildings' corners was based on linear intersections from points measured with the GNSS method. Distances to corners were measured with LEICA DISTO D8, the manual distance meter equipped with $4 \mathrm{x}$ zoom camera, mounted on the pole with the dedicated mount adapter LEICA LSA360. The objective of this work was to provide the reference data for the verification of data acquired from UAS measurements and from cadastral maps. The example of a field sketch is presented in Figure 4.

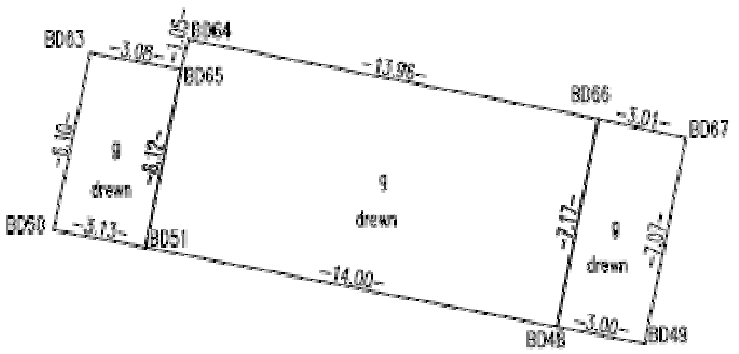

Figure 4. A fragment of a field sketch of the measurements of buildings' corners

\section{RESULTS}

\subsection{The image georeference accuracy analysis}

Image processing was performed using a Pix4D Mapper (Stretcha, 2011). Due to the low precision of flight trajectory recording (an accuracy level of $10 \mathrm{~m}$ ), the fully marked photogrammetric control consisting of 21 of image orientation. Points were measured with the use of GNNS (GPS-RTN) technology using the area corrections from ASG-EUPOS reference stations (the 15 epoch measurement) with the measurement accuracy of $\mathrm{RMS}_{\mathrm{XY}}=0.01 \mathrm{~m}, \mathrm{RMS}_{\mathrm{H}}=0.02 \mathrm{~m}$, 12 points were used as control points and 10 points were used as checkpoints.

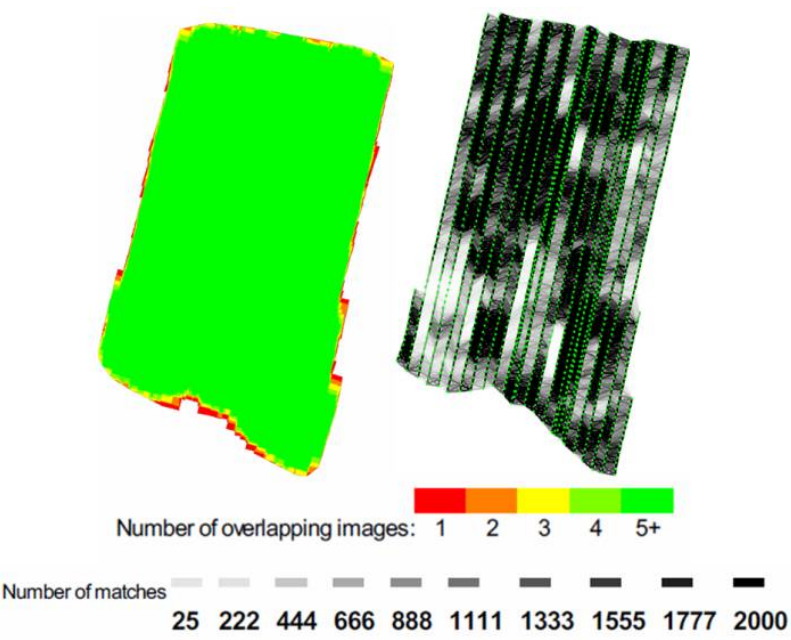

Figure 5. The relative overlap between images and the spatial distribution of the number of image connections 
Tie-points matching was performed with default parameters; the average number of tie-points per image was over 17000 . The detailed analysis of image links (Figure 5b) shows that tiepoints are not evenly distributed and their distribution is strongly associated with the terrain coverage - the number of points decreases on areas covered with bushes and recently ploughed fields. The important increase of connections is visible for the longitudinal overlap. The attempts to perform aerial triangulation with the reduced side overlap caused problems in aerial triangulation of the entire block. The minimum number of tie-points was 1277 and, therefore, the results can be considered satisfactory. Each point of the block was visible in at least five images (Figure 5a) and assuming $80 / 60$ overlap at least six images..

The independent bundle block adjustment was performed with self-calibration, which was performed simultaneously. The accuracies obtained for the control and checkpoints are presented in Table 1; the mean errors of re-projection were equal to 0.2 pixel for tie-points and one pixel for control points. Considering that the GSD $=3 \mathrm{~cm}$, these results should be considered as being correct and satisfactory.

\begin{tabular}{|c|c|c|c|c|}
\hline \multirow{2}{*}{} & \multicolumn{2}{|c|}{ GCP [n=12] } & \multicolumn{2}{c|}{ Check [n=10] } \\
\cline { 2 - 5 } & XY [m] & H [m] & XY [m] & H [m] \\
\hline Mean & 0.0024 & -0.0019 & 0.0011 & -0.0033 \\
\hline Sigma & 0.0259 & 0.0178 & 0.0431 & 0.0525 \\
\hline RMSE & 0.0259 & 0.0179 & 0.0480 & 0.0582 \\
\hline
\end{tabular}

Table 1. The accuracies of image georeferences in the aerial triangulation process (overlap 80/60)

The oriented images were used to generate a point cloud with the average density of 20 points per square metre. Finally, the orthophotomap was generated with the resolution of $3 \mathrm{~cm}$, using the DSM (generated from point clouds) and oriented images, necessary to measure points of the boundaries of cadastral parcels.

\subsection{The analysis of building measurements' accuracy}

Measurements of buildings performed with the use of UAS images were based on the analysis of two options of photogrammetric measurements. The first one was the conventional stereoscopic measurement of buildings' edge points on the selected stereo pair, performed on the photogrammetric Dephos workstation. Efforts were made to the highest possible extent to locate these points as close to the ground's surface as possible; this is important in the case of buildings that are insulated from a certain height and where their elevation varies. In further works, only planimetric coordinates were important and, therefore, in the case when the basement of the building was occluded, the edge points at a certain elevation could have been stereoscopically measured. Measurements were preceded by a selection of a proper stereo pair of images. Most of the objects were visible on several stereo pairs (in the same strip or selecting stereo pairs from adjacent strips, which was possible due to the $80 \%$ end- and $60 \%$ side overlap). Unfortunately, to determine the correct stereo pair was quite difficult task, as the measurement was often impossible when the building was located near the principal point of photo. A small area coverage of used images (approx. $200 \times 130 \mathrm{~m}$ ) had a big impact on the above problem. There have been several situations in which the building, despite the presence of many stereo pairs, had very inconvenient conditions for stereoscopic measurements, as its sidewalls were visible at a very slight angle.

The other measurement method was taking multi-photo monocular measurements involving the photogrammetric intersection to a specific point, which was performed using the Pix4D software. These measurements were much more efficient, because - after point selection in a dense point cloud generated with the image matching - the software showed the visibility of the selected area with all possible images in which a specific corner of a building was visible (Figure 6). Measured points were often visible, even on a dozen images. However, the problem of this method was that the same point had to be indicated in every image, and it was not possible to measure any point on the edge in the case of the basement's occlusion, e.g., when vegetation was growing on the wall of the building. The measurement itself was also more reliable as the measured point was visible from all sides.

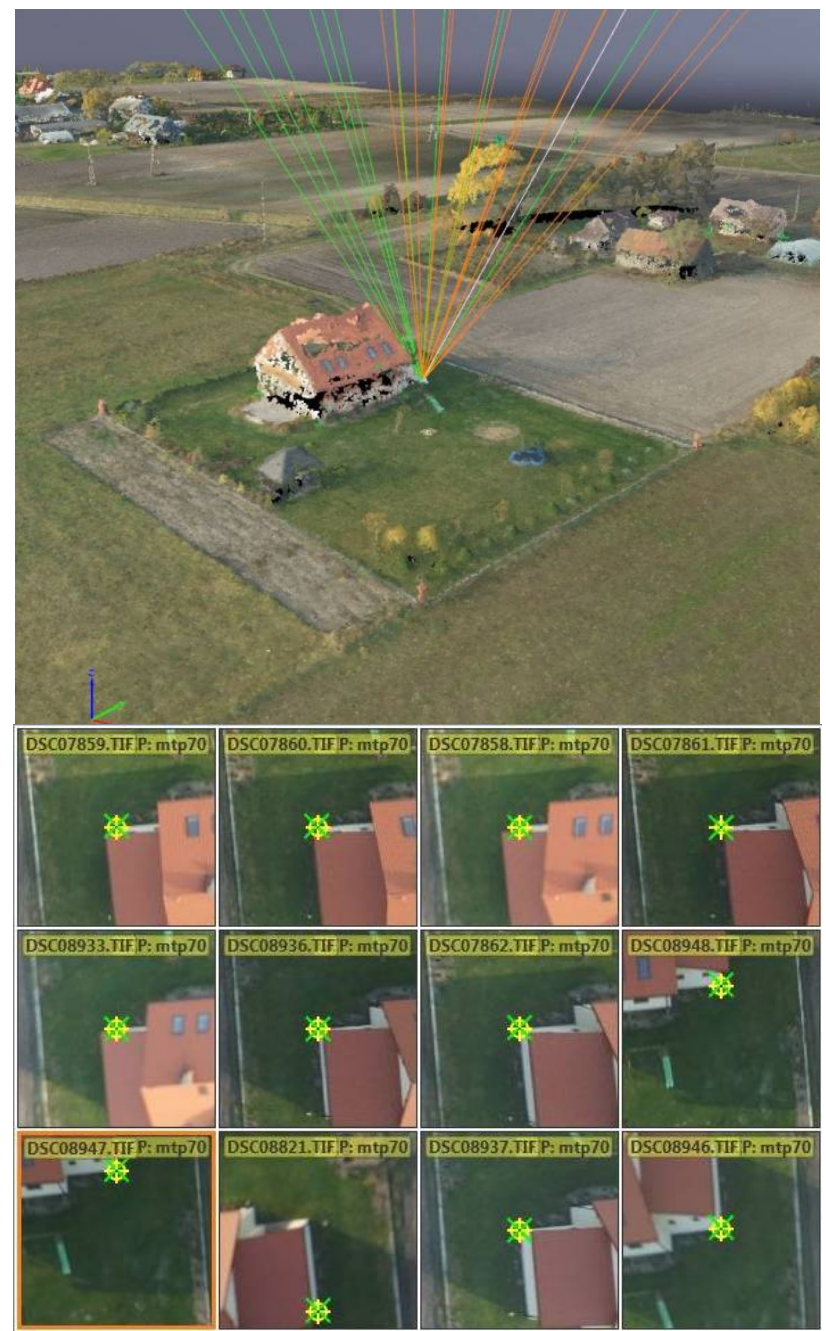

Figure 6. An example of an intersection with the use of the multi-photo measurement method

As part of the experiment, points were measured with the use of stereoscopic and multi-photo measurement methods. Their accuracies were assessed on the basis of direct surveying results (25 for stereoscopic measurements and 30 for multi- 
photo measurements). The preliminary comparative analysis of the data showed that in the case of any photogrammetric measurements, there are many places where it is difficult or impossible to perform such measurements, which is caused by plants located around the houses. A major problem is also created by concrete elements located near the basements of buildings, which often have a similar shade to that of facades. As a result, it was necessary to adopt the criterion for the rejection of an observer's gross errors. Errors that exceeded three times the allowed value for building measurements errors, i.e., $0.3 \mathrm{~m}$, were rejected from the analysis of the accuracy potential of a photogrammetric measurement. The results of the accuracy verification are presented in Table 2, which shows the average value of deviations of the planimetric co-ordinates (the mean for $\mathrm{X}$ and $\mathrm{Y}$ co-ordinates) and the standard deviation, being a measure of the dispersion of coordinate differences. The average value of the error vector with its standard deviation was presented and, finally, the root mean square error (RMS) was calculated. Both methods showed no occurrence of a systematic error ( $\mathrm{dX}$ and $\mathrm{dY}$ errors at the level of aerial triangulation accuracy). Measurements in both methods are characterized by the large scattering of the coordinate difference values (large standard deviation of the differences in $\mathrm{X}$ and $\mathrm{Y}$ ), exceeding the limits of the accuracy of both methods. The mean value of the error vector of point position differences was $0.14 \mathrm{~m}$ for multi-photo measurements and $0.15 \mathrm{~m}$ for stereoscopic measurements, and the root mean square errors of point position for both methods were equal to $0.17 \mathrm{~m}$.

\begin{tabular}{|c|c|c|c|c|c|c|}
\hline \multirow{2}{*}{} & \multicolumn{3}{|c|}{$\begin{array}{c}\text { Stereoscopic }(\mathrm{n}=25) \\
{[\mathrm{m}]}\end{array}$} & \multicolumn{3}{c|}{ Multi-photo $(\mathrm{n}=112)$} \\
\cline { 2 - 7 } & $\mathrm{dX}$ & $\mathrm{dY}$ & $\mathrm{dp}$ & $\mathrm{dX}$ & $\mathrm{dY}$ & $\mathrm{dp}$ \\
\hline MEAN & -0.03 & 0.02 & 0.15 & 0.01 & -0.03 & 0.14 \\
\hline STD & 0.14 & 0.10 & 0.08 & 0.12 & 0.12 & 0.08 \\
\hline RMS & 0.14 & 0.10 & $\mathbf{0 . 1 7}$ & 0.12 & 0.12 & $\mathbf{0 . 1 7}$ \\
\hline
\end{tabular}

Table 2. Accuracies of photogrammetric methods compared to cadastral data

On analysing the table, it was found that, despite the very high image resolution and rejection of gross errors, the results did not meet the expected accuracies. This was caused by the nonuniform accuracy of reference cadastral data and by existing gross errors. Performing further analysis comparing selected points measured photogrammetrically with direct measurements performed for the purpose of the experiment was attempted. The results of this analysis are presented in Table 3 .

\begin{tabular}{|c|c|c|c|c|c|c|}
\hline \multirow{2}{*}{} & \multicolumn{3}{|c|}{$\begin{array}{c}\text { Stereoscopic }(\mathrm{n}=25) \\
{[\mathrm{m}]}\end{array}$} & \multicolumn{3}{c|}{ Multi-photo $(\mathrm{n}=30)$} \\
\cline { 2 - 7 } & $\mathrm{dX}$ & $\mathrm{dY}$ & $\mathrm{dp}$ & $\mathrm{dX}$ & $\mathrm{dY}$ & $\mathrm{dp}$ \\
\hline MEAN & 0.03 & 0.00 & 0.16 & -0.01 & 0.00 & 0.09 \\
\hline STD & 0.13 & 0.14 & 0.11 & 0.06 & 0.09 & 0.05 \\
\hline RMS & 0.13 & 0.14 & $\mathbf{0 . 1 9}$ & 0.06 & 0.09 & $\mathbf{0 . 1 0}$ \\
\hline
\end{tabular}

Table 3. Accuracies of photogrammetric methods compared to the field measurements

The verification of photogrammetric measurements in relation to the direct surveying measurements was performed for 25 stereoscopic points and 30 multi-photo points, for which the corresponding coordinates have been successfully collected in the field. Similarly, in this case, no systematic errors were observed that achieved the values of $\mathrm{dX}$ and $\mathrm{dY}$ close to zero. In this case, the stereoscopic measurement method allowed us to achieve an accuracy similar to that of the previous analysis. The point position error was $0.19 \mathrm{~m}$. Much better results were obtained for multi-photo measurements, for which the mean square error reached the value of $0.10 \mathrm{~m}$ and the average value of the planimetric position differences vector was $0.09 \mathrm{~m}$.

\subsection{Possibilities of measuring parcels' boundaries}

Referring to parcels' boundary measurements, the legal standards in Poland say that if there is no archive documentation concerning the boundaries of cadastral parcels, or if recorded data are not reliable, data on the location of boundaries of the cadastral parcels are obtained as a result of field surveying or photogrammetric measurements preceded by determining the course of these boundaries in the presence of owners of both neighbouring parcels. Identification of the cadastral parcels' boundaries, including the location of border points defining these boundaries, may be performed based on orthophotomaps from aerial or satellite images, if such images are characterized by the resolution providing the visualization of features that may be relevant in determining the course of these boundaries. Thus, identification made of the owners of adjacent parcels can be performed in the field or, if the photogrammetric product is characterized by the suitable resolution that enables identification of features defining the boundary, it can be performed at the office, without going to the field.

It should be noted that parcels' boundaries points are not marked in the field by permanent border points. The most common form of boundaries is the field is the balk. Such baulks are visible on the orthophotomap due to the tonal difference between neighbouring parcels in which different land cover/use exists. In this experiment, the points of parcels' boundaries identified on the orthophotomap were the subject of measurements. Their location has been verified based on the existing cadastral data. Quite often there are cases of different crops on a single parcel, clearly visible in the field and on the orthophotomap. The boundaries of the cultures are, however, not measured. During the measurements, the superimposition of the boundaries from the cadastral map on the orthophotomap proved to be useful. It allowed us to avoid incorrect measurements of land-use borders, which were not, however, the borders of the parcels. The current boundary point is often not clearly visible, either in the field or on the orthophotomap. This is due to agricultural operations performed with agricultural machinery. This causes considerable confusion in the interpretation of points of boundaries during the measurement stage. Figure 7 shows fragments of the orthophotomap with superimposed borders from cadastral data, taken as a reference. These examples illustrate possible difficulties in the interpretation of the course of boundaries on the orthophotomap.

Table 4 illustrates the resulting accuracy of the boundary measurement on the orthophotomap in relation to the cadastral data, performed by two observers. The preliminary comparative analysis of the data showed that in the case of the cartographic measurements on the orthophotomap, many places exist where the cadastral boundary does not coincide with a visible land use boundary. These problems made it necessary to adopt the criterion for the rejection of observer's significant gross errors. Errors that exceeded by three times the allowed 
value for an error in parcel boundary measurements, i.e., $0.90 \mathrm{~m}$ were rejected from the analysis of the accuracy potential of cartographic measurements of the cadastral parcels' boundaries. It can be seen that the measurements presented in Table 4 are characterized by quite significant errors exceeding the acceptable value of $0.30 \mathrm{~m}$. It should be noted that these errors consist of:

- reference data errors (cadastral data),

- errors of cartographic measurement (monoplotting of the orthophotomap),

- errors of parcels' boundary points' identification in the field and on the orthophotomap.

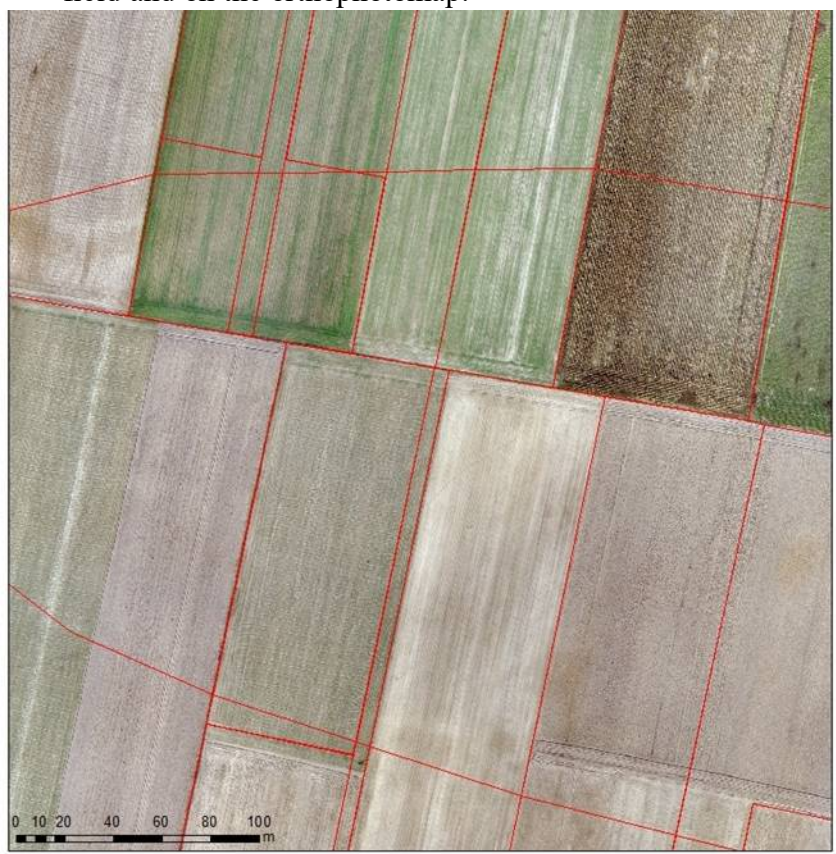

\begin{tabular}{|c|c|c|}
\hline & $\begin{array}{c}\text { Monoplotting } \\
\text { Observer 1 } \\
(\mathrm{n}=150)[\mathrm{m}]\end{array}$ & $\begin{array}{c}\text { Monoplotting } \\
\text { Observer 2 } \\
(\mathrm{n}=35)[\mathrm{m}]\end{array}$ \\
\hline MEAN & 0.33 & 0.40 \\
\hline STD & 0.24 & 0.25 \\
\hline RMS & 0.41 & 0.48 \\
\hline
\end{tabular}

Table 4. The accuracies of cartographic measurements on the orthophotomap (the error vector) in relation to the cadastral data

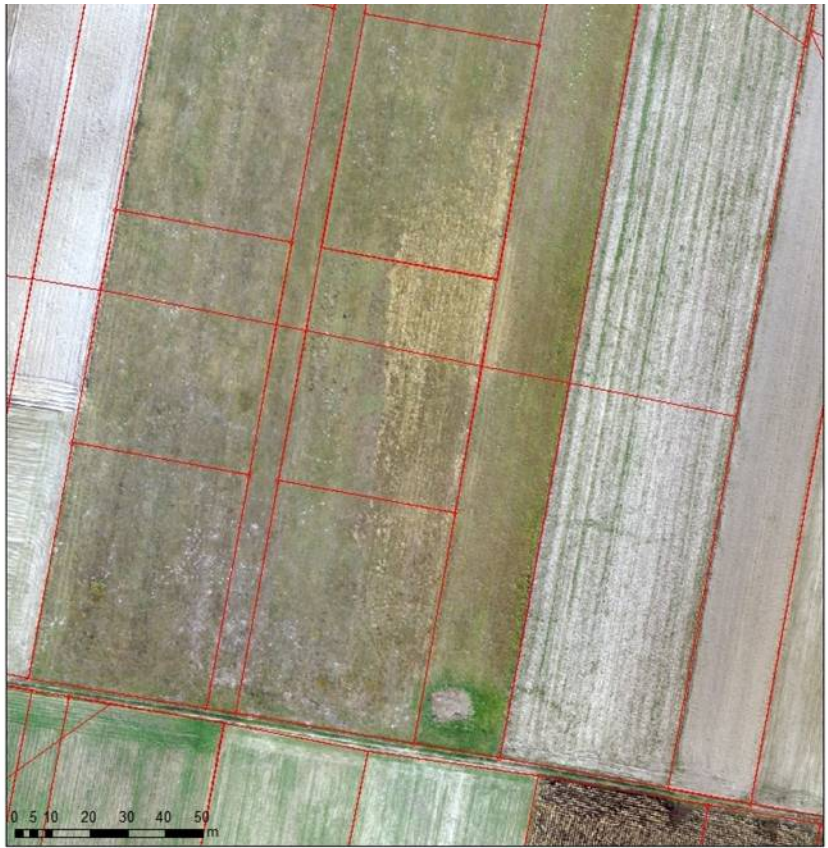

Figure 7. An example of discrepancies between boundaries existing in the cadastre and real land-use conditions detected on the basis of products from the UAS platform

Among these errors, the most important is the error of parcels' boundary points' identification, influenced by a limited possibility of boundary course interpretation on the orthophotomap. In the case when such boundary designation is performed in an office (without going to the field), the problem of boundary interpretation is not even considered if both parties amicably present the discussed boundary. The accuracy of photogrammetric works and the resolution of the orthophotomap used allow us to fully prepare such a geodetic act, and the most important issue is to interpret the location of the discussed boundary.

\section{CONCLUSIONS}

Stereoscopic measurements of building edges at an arbitrary elevation (assuming its verticality) in the case of UAS images is difficult for buildings located in the nadir part of an image, when the location of measured buildings near the edge of images is desired. It is significantly limited by the small image area associated with small format cameras typically used in low altitude photogrammetry. A major limitation of this measurement technique using the UAS imagery is the very frequent need to change the stereo pair, as well as from the need to select the optimum stereo pair for a given location. The performed flights that do not keep perfectly comparable side lap make it difficult to assess whether the adjacent stereo pair is suitable. The increased image overlaps (end- and side overlaps) also increase the number of stereo pairs that may be selected; this results in the increase of the possibilities and accuracies of measurements. Each corner of the building (the edge) is projected and visible on many images, which is important for the multi-photo measurements performing photogrammetric intersection with monocular observation. This method, used by the UAS' data-processing software, zooms in to the approximate measurement of locations on all visible images that influence the efficiency of measurements. Additionally, more redundant measurements exist. The results of this experiment can be considered as the proof of the superiority of multi-photo measurements over stereoscopic measurements. For photogrammetric measurements, better results were derived from the multi-photo measurements method, compared to the in-the-field measurements. The high accuracy requirements for building measurements exclude the measurements of the roof edges, due to the existing eaves (roof edges do not coincide with the outline of the building).

Measurement of the corners of cadastral parcels' boundaries on the orthophotomap (the monoplotting technique) is a proper technique. The main limitations of the accuracy of such 
measurements are the identification error of parcel boundaries' points on the orthophotomap caused by the ambiguous course in the field (e.g., the impact of agro-technical works) and the lack of knowledge of the course of boundaries, which is decided by interested parties.

The paper shows the potential and limits of the use of UAS for the needs of cadastral works. It also presents recommendations to perform photogrammetric missions, as follows:

- the end- and side overlaps should be significantly larger than in the case of typical, large-format photogrammetric blocks,

- the decrease of overlaps below the value of $80 \%$ (end overlap) and $60 \%$ (side overlap) is not recommended, as it may result in incorrect aerial triangulation results and, as a consequence, problems in orthophotomap generation or photogrammetric measurements using exterior orientation of images, which in turn are used in the works concerning the updating the cadastre,

- the marked photogrammetric control is necessary, measured with a $2-3 \mathrm{~cm}$ accuracy,

- when using UAS images, the reduced quality of such images should be realized, especially their limited resolving power. It can be determined by comparing the resolving power of images of the same pixel (the same GSD) taken with UAS and images taken with largeformat, photogrammetric cameras. The poorer quality of the UAS images is reflected in the reduced possibility of correctly interpreting those images. Considering this, it is recommended to utilize images acquired by means of UAS platforms with the ground pixel size smaller than $0.05 \mathrm{~m}$.

The accuracy of photogrammetric works $(0.05 \mathrm{~m})$ demonstrated in this experiment is sufficient to ensure the measurement accuracy of $0.10 \mathrm{~m}$ for buildings and it is also sufficient to measure the cadastral boundary on the orthophotomap. However, the accuracy of the measurements of buildings and boundaries is lower in this study. It proved that the most important issue is not connected with the accuracy of measurements but with the ability to interpret the measured features, which is related to the geometric and radiometric quality of images, as well as the observer's experience.

\section{ACKNOWLEDGEMENTS}

The authors would like to thank the MSP company for its cooperation with photogrammetric works, providing UAV images used in the presented experiments. The authors also thank Mr Dariusz Pręgowski - the Warsaw-Western district county surveyor for his assistance in obtaining reference data.

\section{REFERENCES}

Colomina, I., \& Molina, P., 2014. Unmanned aerial systems for photogrammetry and remote sensing: A review. ISPRS Journal of Photogrammetry and Remote Sensing, 92, 79-97.

Dale P.F., 1979. Photogrammetry and Cadastral Surveys within the commonwealth. Photogrammetric Record, 9 (53): 621-631.

Jazayeri, I., Rajabifard, A., \& Kalantari, M., 2014. A geometric and semantic evaluation of 3D data sourcing methods for land and property information. Land Use Policy, 36, 219-230.

Kelm, K., 2014. UAVs Revolutionise Land Administration. GIM International, 28(10), 35-37.
Kędzierski, M., Fryśkowska, A., Wierzbicki, D., \& Deliś, P. (2015). Cadastral Mapping Based on UAV Imagery. In 15th International Scientifi $\mathrm{c}$ and Technical Conference "From imagery to map: digital photogrammetric technologies" (pp. 12-15).

Kurczyński Z., Bakuła, K., 2016. Possibility assessment of modern photogrammetry for works related to land and building register, VIII Ogólnopolskie Sympozjum Geoinformatyczne, Warszawa-Serock.

Manyoky, M., Theiler, P., Steudler, D., \& Eisenbeiss, H., 2012. Unmanned Aerial Vehicle in Cadastral Applications. ISPRS - International Archives of the Photogrammetry, Remote Sensing and Spatial Information Sciences, XXXVIII1/(September), 57-62.

Schermerhorn, W., Witt, G. F. (1954). Photogrammetry for cadastral survey. Photogrammetria, 10, 45-57.

Srinivas, P., Venkataraman, V. R., Jayalakshmi, I., 2012. Digital Aerial Orthobase for Cadastral Mapping. Journal of the Indian Society of Remote Sensing, 40(3), 497-506.

Strecha, C., 2011. Automated photogrammetric techniques on ultra-light UAV imagery. Pix4D.

Weissmann, K., 1971. Photogrammetry applied to cadastral survey in Switzerland. The Photogrammetric Record, 7, 5-15. 